\title{
Behavior of Lime-Stabilized Red Bed Soil after Cyclic Wetting-Drying in Triaxial Tests and SEM Analysis
}

\author{
Zhengmin Song, ${ }^{1,2}$ Dewen Zhang, ${ }^{3}$ Yuncheng Mao, ${ }^{2}$ Yanhu Mu $\mathbb{D}^{2}{ }^{2}$ Kun Zhang, \\ and Qinglong Zhang ${ }^{4}$ \\ ${ }^{1}$ School of Civil Engineering, Lanzhou Univ. of Tech., Lanzhou, Gansu 730050, China \\ ${ }^{2}$ State Key Laboratory of Frozen Soils Engineering, Northwest Institute of Eco-Environment and Resources, \\ Chinese Academy of Sciences, Lanzhou, Gansu 730000, China \\ ${ }^{3}$ Gansu Civil Aviation Construction Co., Ltd., Lanzhou 730050, China \\ ${ }^{4}$ Gansu Provincial Transportation Research Institute Group Co., Ltd., Lanzhou 730050, China \\ Correspondence should be addressed to Yanhu Mu; muyanhu@lzb.ac.cn
}

Received 6 November 2019; Revised 8 February 2020; Accepted 6 March 2020; Published 8 April 2020

Academic Editor: Carlos R. Rambo

Copyright (c) 2020 Zhengmin Song et al. This is an open access article distributed under the Creative Commons Attribution License, which permits unrestricted use, distribution, and reproduction in any medium, provided the original work is properly cited.

\begin{abstract}
Most red beds demonstrate inferior geotechnical properties in natural conditions and need to be improved when used as construction material. In this study, a serious of triaxial tests, permeability tests, and scanning electron microscopy (SEM) analysis were carried out on lime-stabilized and untreated red bed soil after experiencing different wetting-drying (W-D) cycles. The test results showed that, with the increase in the added lime, the shear strength, strength parameters (including the cohesion and the internal friction angle), and the shear modulus of red bed soil increased gradually. For the untreated specimens, the four parameters decreased considerably after experiencing W-D cycles, while for the lime-stabilized specimens, they generally increased with an increase in the W-D cycles. Without experiencing the W-D cycles, the permeability coefficient increased by two times after it was stabilized with $10 \%$ lime. But with an increase in the W-D cycles, the permeability coefficient of the untreated and lime-stabilized specimens continuously increased and significantly decreased, respectively. Finally, variations in microstructure of the red bed soil under the effects of the lime stabilization and W-D cycles were discussed based on the SEM analysis. The results may contribute to improvement of red bed soil when used as roadbed and airfield fillings.
\end{abstract}

\section{Introduction}

Red beds are detrital sedimentary rocks that are widely distributed in tropical and subtropical areas all over the world $[1,2]$. In China, the red beds are also widely distributed in southwest and northwest regions, with a total exposed area of approximately 0.826 million $\mathrm{km}^{2}$ [3]. In natural conditions, most red beds generally demonstrate inferior geotechnical properties due to inclusion of clay and soluble and/or organic minerals [4]. Their lower strength, significant rheology, and a certain swelling property can cause various geological hazards and infrastructure damages [5]. Thus, when used as subgrade filling, the red beds need to be improved carefully either using physical or chemical methods $[4,5]$.
Lime is a prevalent and effective additive that has been widely used for soil stabilization. Previous studies showed that lime addition can increase the optimum water contents, shrinkage limits, and strengths of the mixtures but decrease the liquid limits, plasticity indexes, and maximum dry densities of the mixtures [6-13]. However, in engineering practice, there are lots of environmental conditions which can affect the effect of chemical stabilization of soil foundations. Due to alternation of wet and dry seasons, cyclic wettingdrying $(\mathrm{W}-\mathrm{D})$ is a very common phenomenon in shallow ground. Rao et al. [14] observed a negative effect of the W-D cycles on lime-stabilized and wood-ash-modified black cotton soil. Ye et al. [15] described variations in the unconfined compression strength and the Atterberg limits of expansive 
soils improved by industrial wastes with the W-D cycles. Wang et al. [16] showed that the strength of expansive soil improved by $0.3 \%$ OTAC (octadecyl trimethyl ammonium chloride)-3\%KCL lost gradually with the W-D cycles. Guney et al. [17] investigated impacts of cyclic W-D on swelling behavior of lime-stabilized soil and found that the initial beneficial effect of lime stabilization was lost after the first W-D cycle. Akcanca and Aytekin [18] found that the beneficial effect of lime stabilization to control the swelling pressures of sand-bentonite mixtures would be partly lost by the W-D cycles, while in Yazdandoust and Yaarobi's study [19], investigation on effect of cyclic W-D on swelling behavior of plymer-stabilized expansive clays showed that the beneficial effect of polymer stabilization would be preserved.

Till date, there exist limited studies regarding the impact of W-D cycles on the mechanical properties of lime-stabilized red bed soils. In this study, red bed soils taken from Northwest China were stabilized by lime with different ratios $(0,3,5$, and $10 \%)$, followed by exposure to different $\mathrm{W}$-D cycles $(0,1,5$, and 20). Subsequently, unconsolidated-undrained triaxial tests, permeability tests, and SEM analysis were conducted to investigate the impact of W-D cycles on the mechanical properties of lime-stabilized soil. Based on these tests, effects of the W-D cycles on the stress-strain behavior, unconfined compressive strength and strength parameters, shear modulus, permeability, and microstructure were analyzed in detail. The obtained results may provide useful information for evaluating the long-term stability of foundation soils stabilized by lime in red bed areas.

\section{Soil and Lime}

The tested soil was taken from Chengzhou Airport $\left(105^{\circ} 7^{\prime} 14.23^{\prime \prime} \mathrm{E}, 33^{\circ} 75^{\prime} 31.75^{\prime \prime} \mathrm{N}\right.$, and $1023 \mathrm{~m}$ a.s.l) in Chenxian Country, Gansu Province, at depths ranging from 2 to $5 \mathrm{~m}$. The red beds were widely encountered within the depths. The disturbed soil was excavated, placed in plastic bags, and transported to the State Key Laboratory of Frozen Soil Engineering, Northwest Institute of Eco-Environment and Resources, Chinese Academy of Sciences.

The collected soil was air-dried, pulverized, and sieved to remove large particles. After that, the index properties of the red bed soil are tested and listed in Table 1. It can be seen that the free swell index was $45.5 \%$. In the Specifications for Design of Highway Subgrades (JTG D30-2015) [20], soils are classified as nonexpansive $\left(\delta_{\text {ef }}<40\right)$, low expansive $\left(40 \leq \delta_{\text {ef }}<60\right)$, medium expansive $\left(60 \leq \delta_{\text {ef }}<90\right)$, and high expansive $\left(\delta_{\text {ef }} \geq 90\right)$ based on the free swell index. Thus, the tested soil can be classified as low-expansive soil according to the specification.

The lime used in this study is commonly used hydrated lime (the major ingredient is $\left.\mathrm{Ca}(\mathrm{OH})_{2}\right)$. At room temperature (about $20^{\circ} \mathrm{C}$ ), the lime is a white crystalline powder with trace water.

\section{Experimental Program}

3.1. Specimen Preparation. Both the untreated and limestabilized specimens were prepared with the static
TABLE 1: Index properties of red bed soil used in this study.

\begin{tabular}{lc}
\hline Characteristics & Value \\
\hline Gravel content (\%) & 29.8 \\
Sand content (\%) & 66.7 \\
Silt/Clay content (\%) & 3.5 \\
Optimum moisture content (\%) & 11.2 \\
Maximum dry density $\left(\mathrm{g} \cdot \mathrm{cm}^{-3}\right)$ & 2.01 \\
Liquid limit (\%) & 25.1 \\
Plastic limit (\%) & 15.3 \\
Free swell index (\%) & 45.5 \\
Plasticity index & 9.8 \\
\hline
\end{tabular}

compaction method specified in GB/T 50123-2019 [21]. According to previous studies on lime-stabilized soils [22], four ratios of added lime (RALs) $(0,3,5$, and $10 \%$ by the parent soil weight) and four different W-D cycles $(0,1,5$, and 20) were chosen in this study. All the test specimens were compacted at the respective maximum dry density and optimum moisture content. The height and diameter of the specimens were $80 \mathrm{~mm}$ and $39.1 \mathrm{~mm}$, respectively. All the prepared specimens were wrapped with thin plastic film and stored in a curing box $\left(20 \pm 0.5^{\circ} \mathrm{C}, 96 \pm 1 \% \mathrm{RH}\right)$ for 28 days before the following W-D cycles.

3.2. W-D Cycles. A W-D cycle corresponds to a soil specimen being wetted and allowed to swell, followed by it being dried to its initial dry unit weight at an ordinary condition, then wetted again to swell, which is one W-D cycle. Here, the specimen was filled with water and allowed to fully swell for at least $24 \mathrm{~h}$. Subsequently, the water was removed and the saturator was dismantled. The specimen was then allowed to air-dry at room temperature (about $20^{\circ} \mathrm{C}$ ) to its initial dry unit weight. All dried specimens were carefully weighed before proceeding with the next W-D cycle. In this study, the W-D cycles that the specimens subjected to were $0,1,5$, and 20 , respectively. The pictures of the specimens after the wetting and drying are shown in Figure 1.

3.3. Triaxial Test. Conventional undrained triaxial tests were conducted on the saturated untreated and lime-stabilized specimens using a strain-controlled system (ASTM D285015) [23]. The detailed diagram of the instrument and principle is shown in Figure 2. The confining pressures chosen in this study were 50,100 , and $150 \mathrm{kPa}$, and the strain rate was $0.8 \mathrm{~mm} / \mathrm{min}$. The maximum axial strain reached in a triaxial test was determined by the specimen failure mode. If the specimens failed in a strain-hardening mode, the maximum axial strain was $15 \%$; however, if the specimens failed in a strain-softening mode, the maximum axial strain was $12 \%$.

3.4. Permeability Test. The falling head test was adopted in this study. The first step in carrying out the permeability test was to saturate the specimen in the mold. Afterwards, the subsequent saturation process and permeability test were carried out according to the Standard for Soil Test Method 


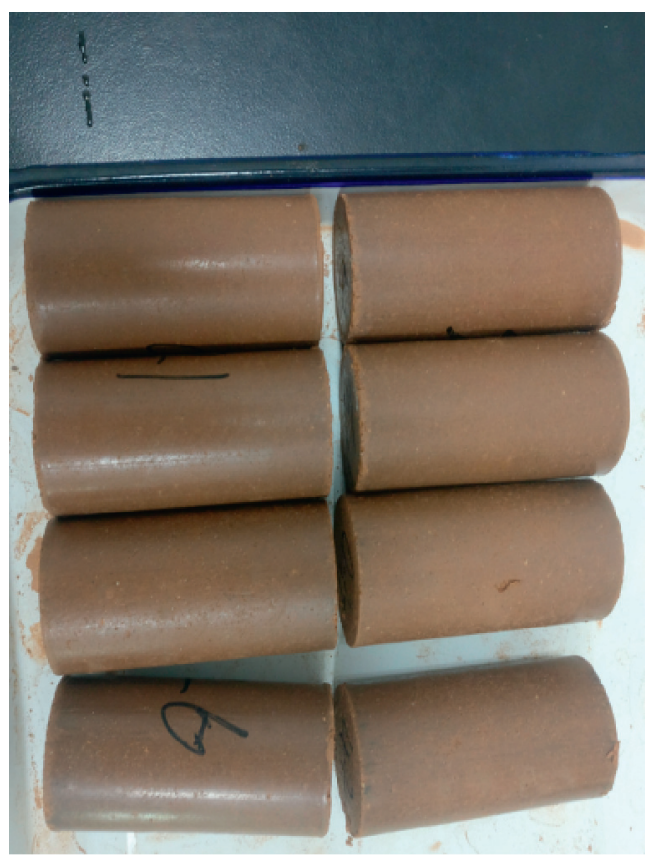

(a)

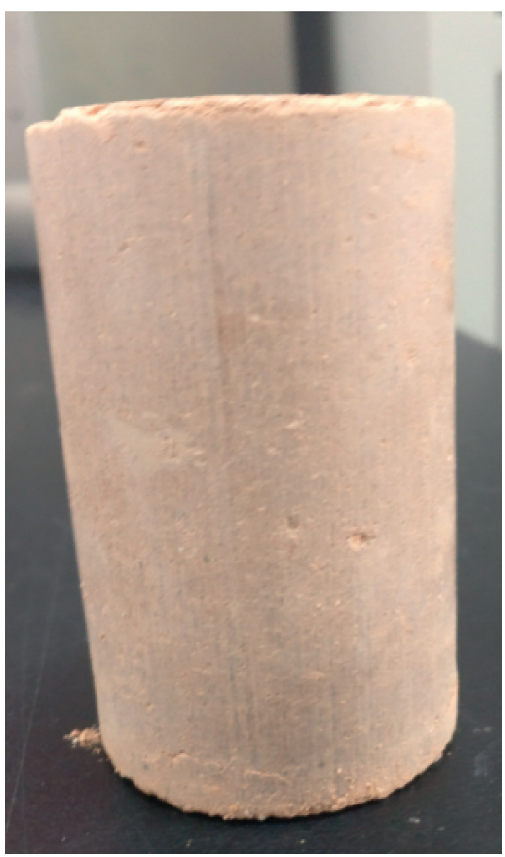

(b)

Figure 1: Specimens after the wetting (a) and drying (b).

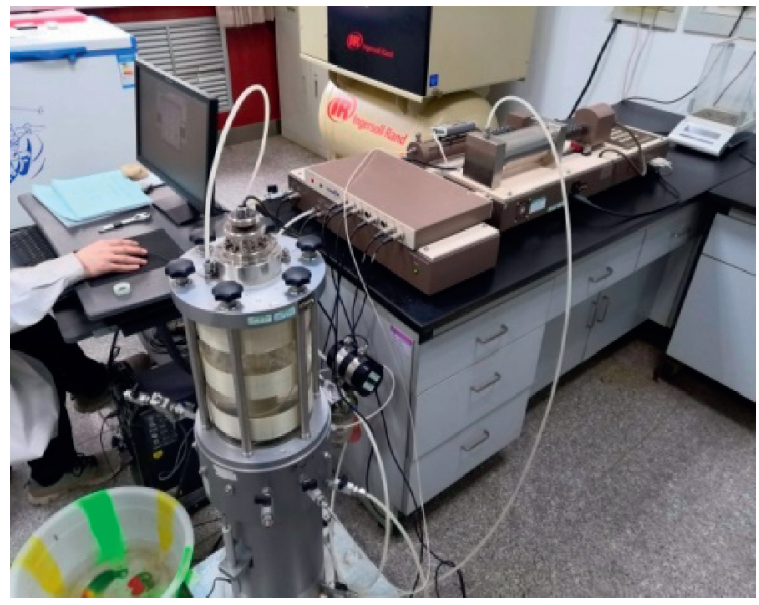

(a)

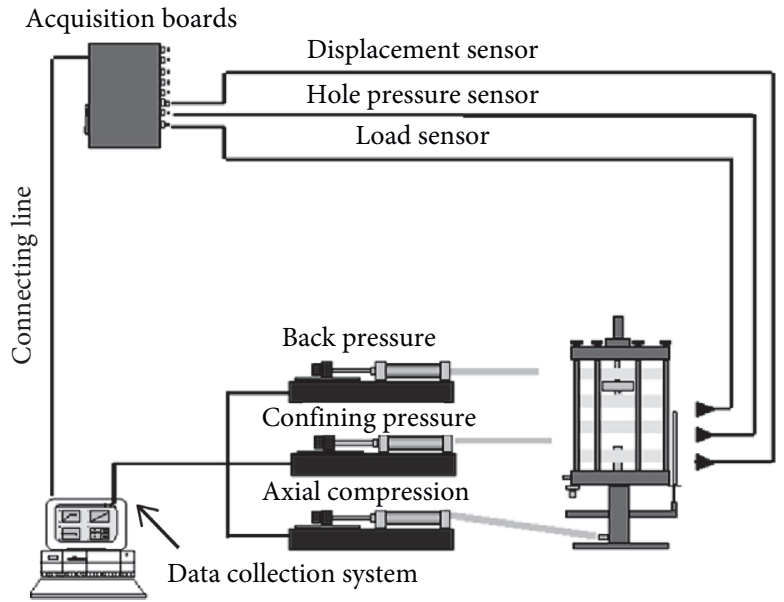

(b)

Figure 2: Triaxial test equipment used in this study (a) and its schematic diagram (b).

GB/T 20123-1999. The permeability coefficient was calculated as

$$
k_{T}=2.3 \frac{a L}{A\left(t_{2}-t_{1}\right)} \log \frac{H_{1}}{H_{2}},
$$

where a is the section area of variable head pipe $\left(\mathrm{cm}^{2}\right) ; L$ is the specimen height $(\mathrm{cm})$; A is the cross-sectional area of the specimen; and $t_{1}$ and $t_{2}$ are test start and end times, while $H_{1}$ and $H_{2}$ are test start and end water head.

3.5. SEM. SEM analysis was carried out on the parallel specimens to observe the variations in the soil structure after the lime addition and W-D cycles. The SEM equipment used was a Quanta250 electron microscope analysis system manufactured by the American FEI Technology company. Before the test, the prepared scanning specimen was first pumped to a vacuum state, and then the specimen surface was plated with gold. Subsequently, the scanned specimen was placed in Quanta250 for microstructure observation at magnifications of $\mathrm{x} 100, \mathrm{x} 500, \mathrm{x} 1000 \times 5000$, and $\mathrm{x} 10000$ times.

\section{Results and Analysis}

4.1. Effect of W-D Cycles on Stress-Strain Behavior of Red Bed Soil. Stress-strain curves of the untreated and lime-stabilized specimens are presented in Figure 3. The stress-strain 


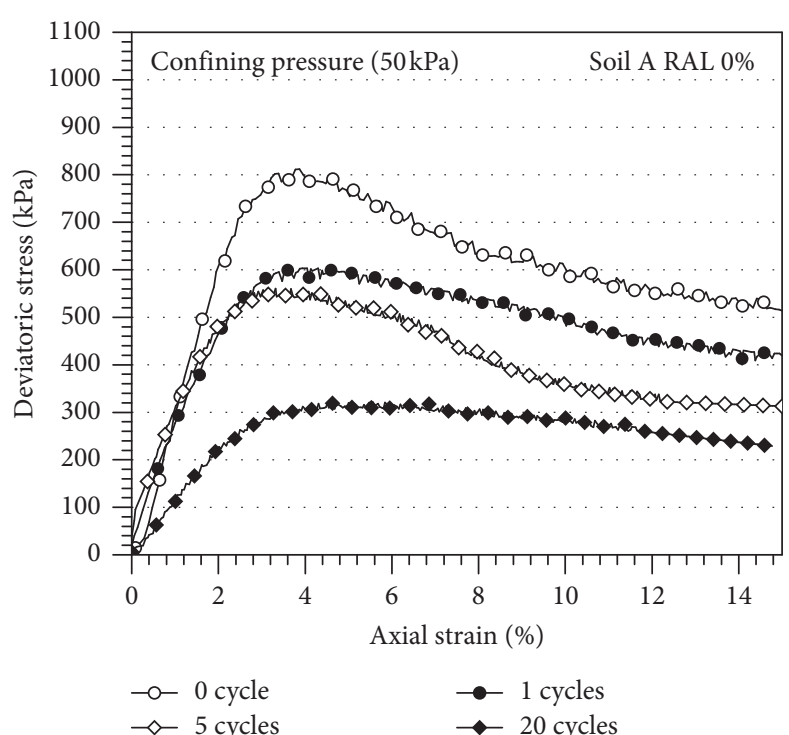

(a)

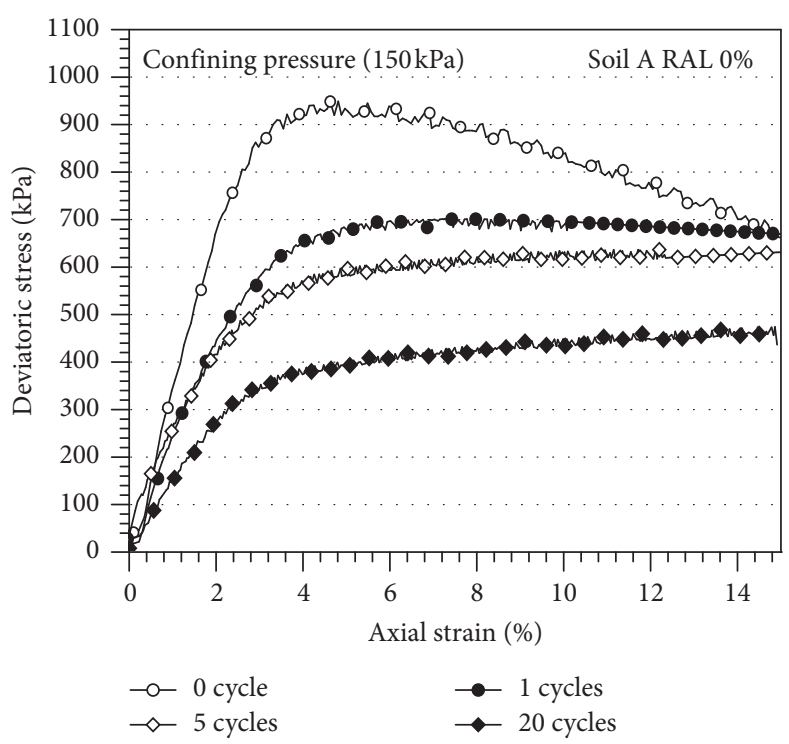

(c)

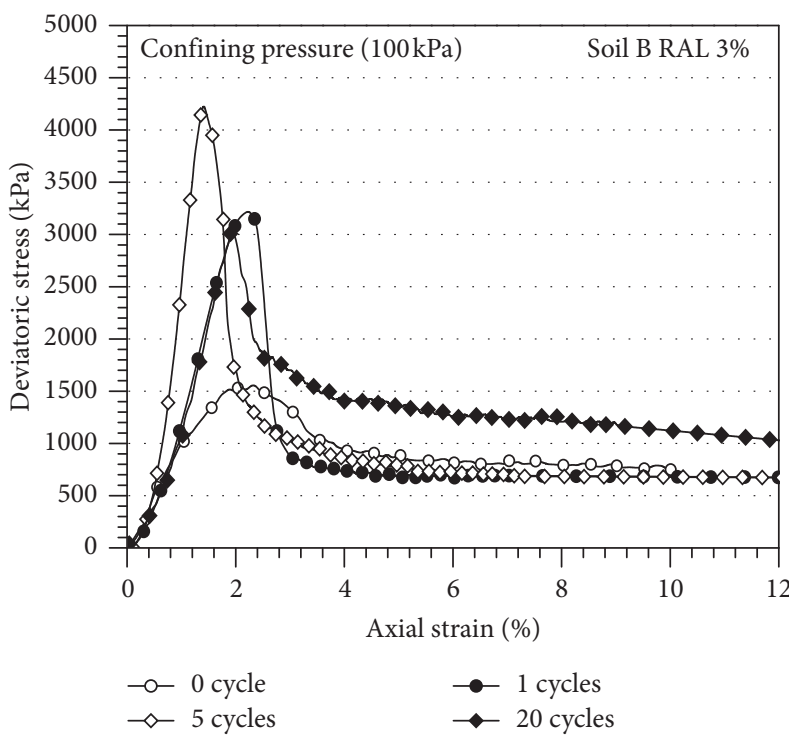

(e)

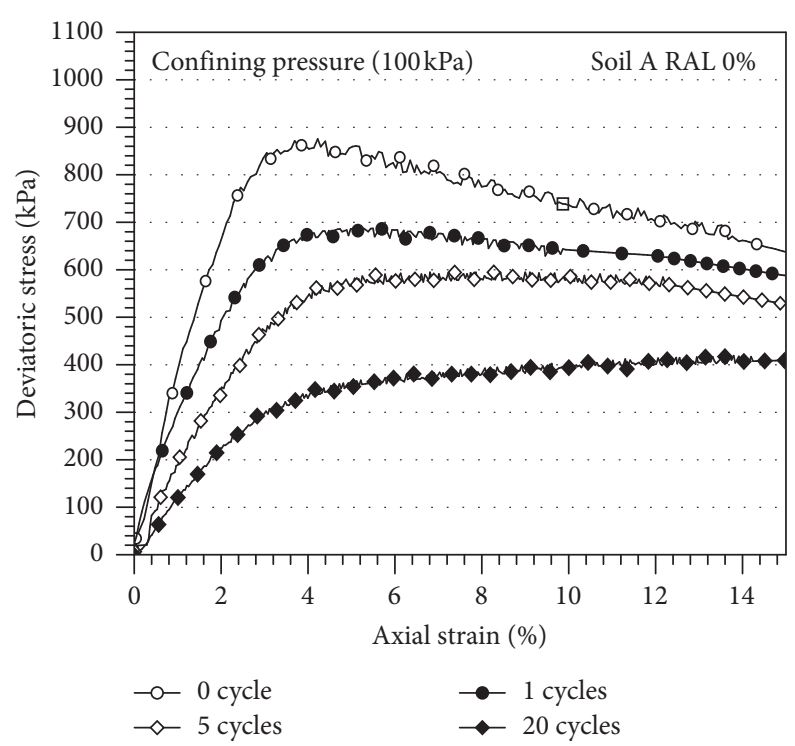

(b)

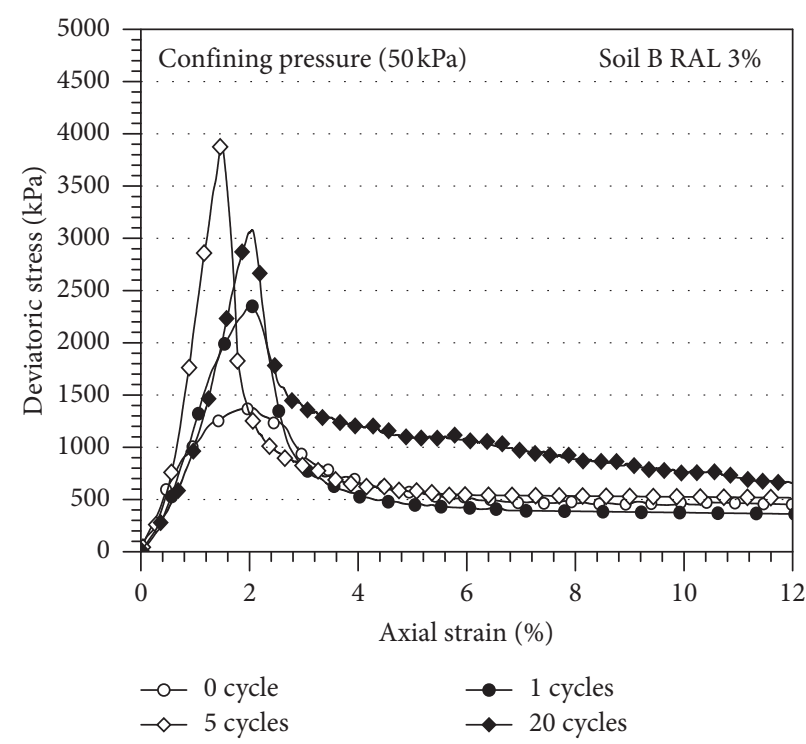

(d)

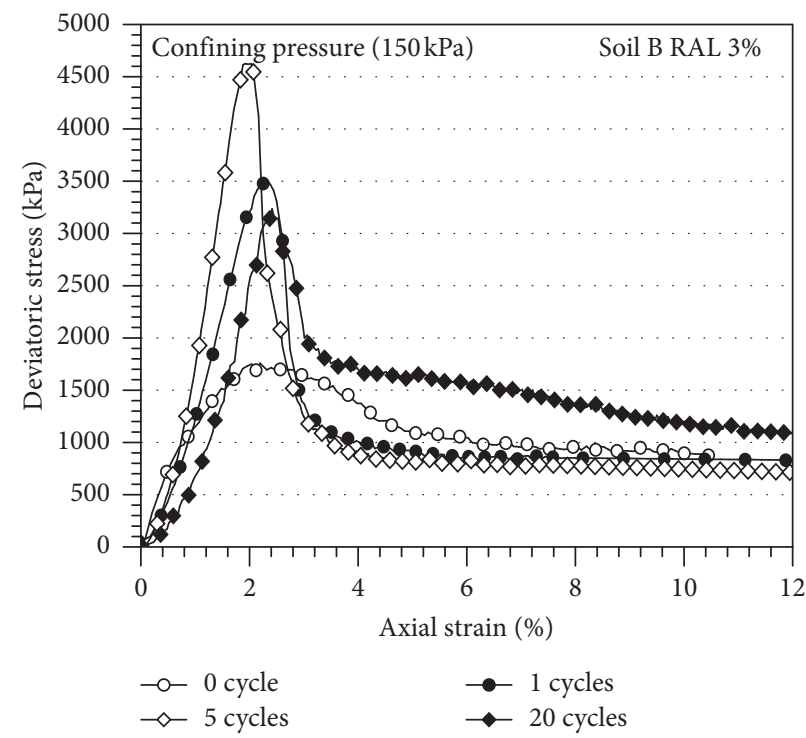

(f)

FIgURE 3: Continued. 


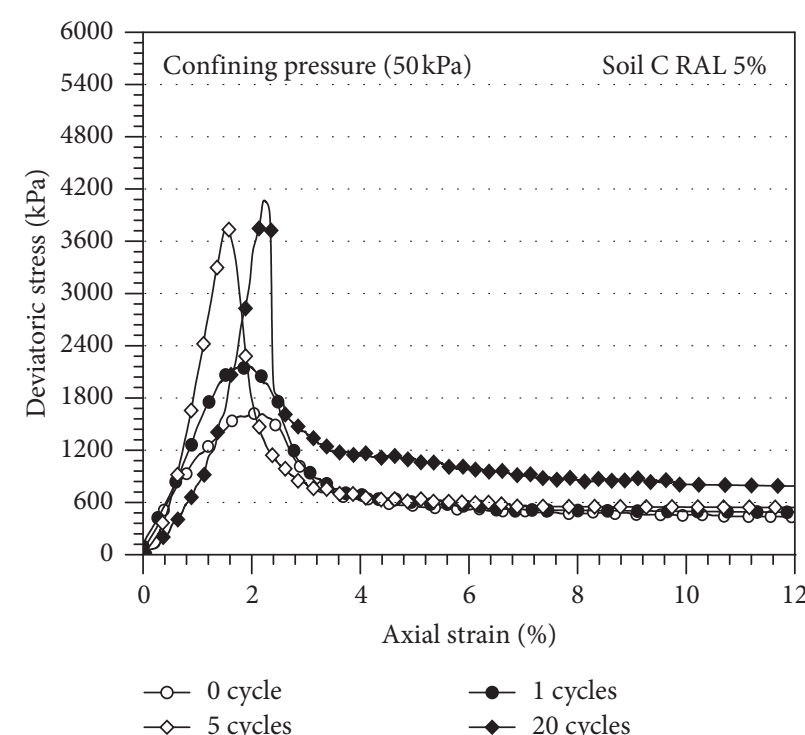

(g)

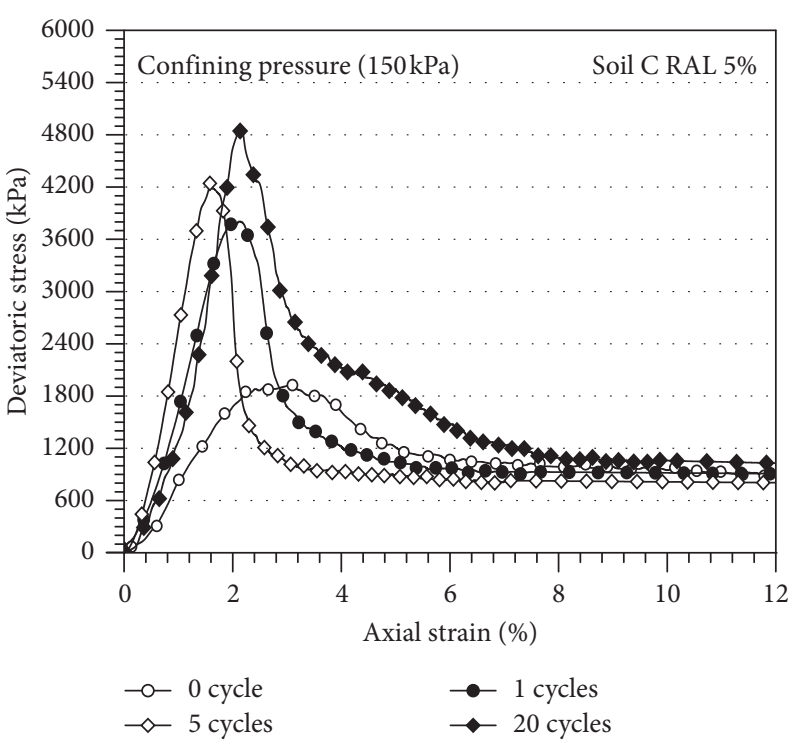

(i)

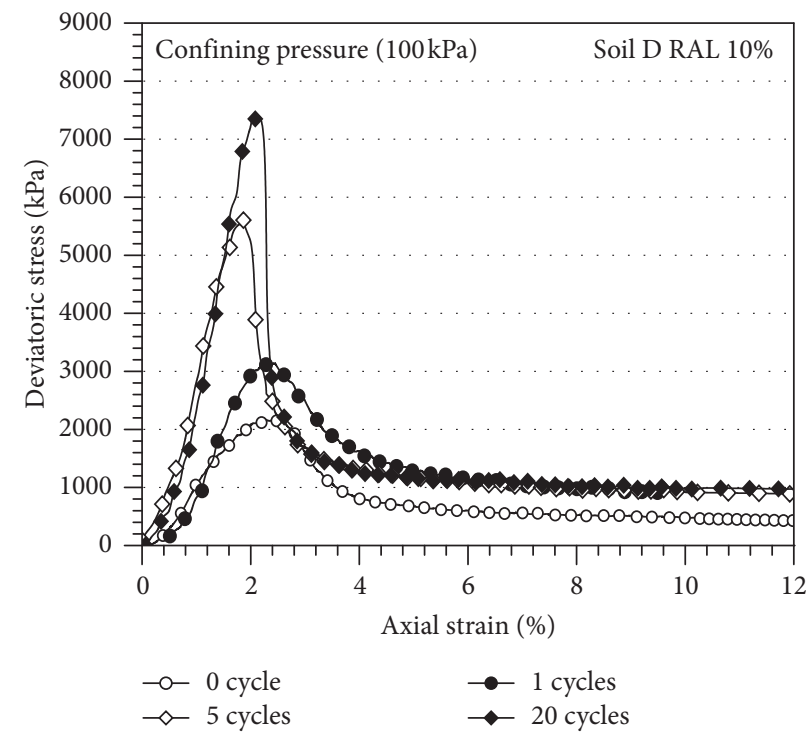

(k)

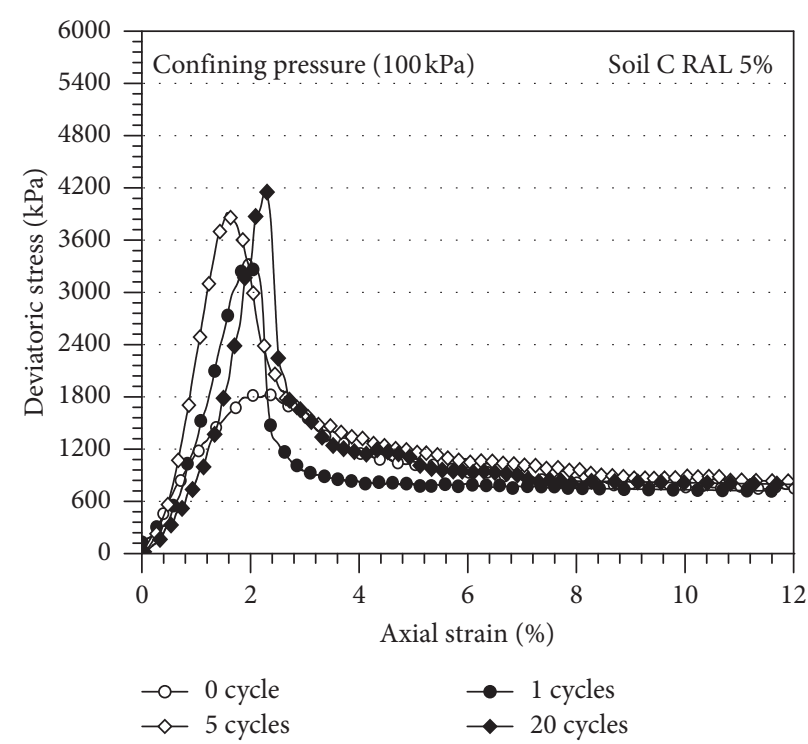

(h)

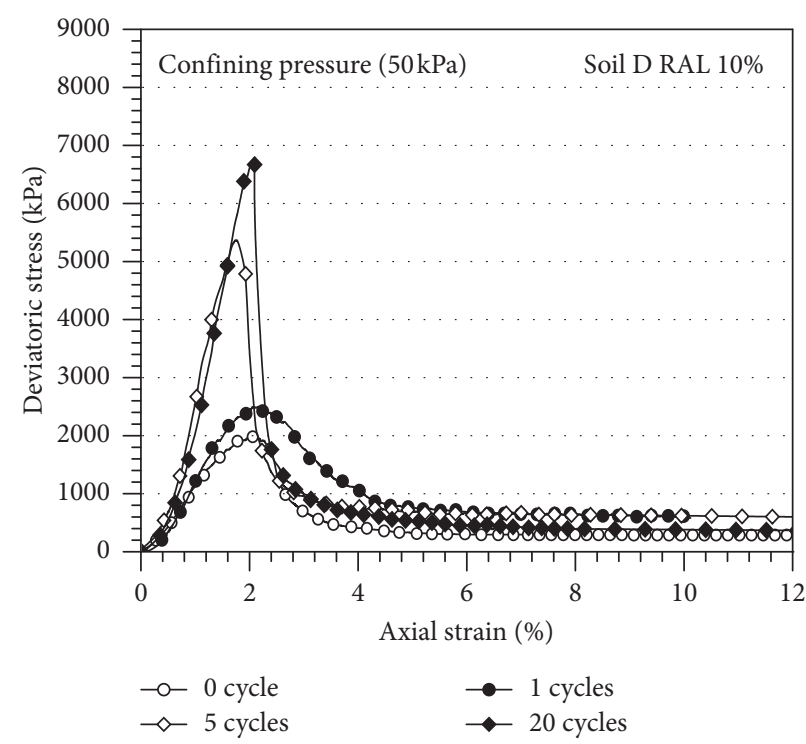

(j)

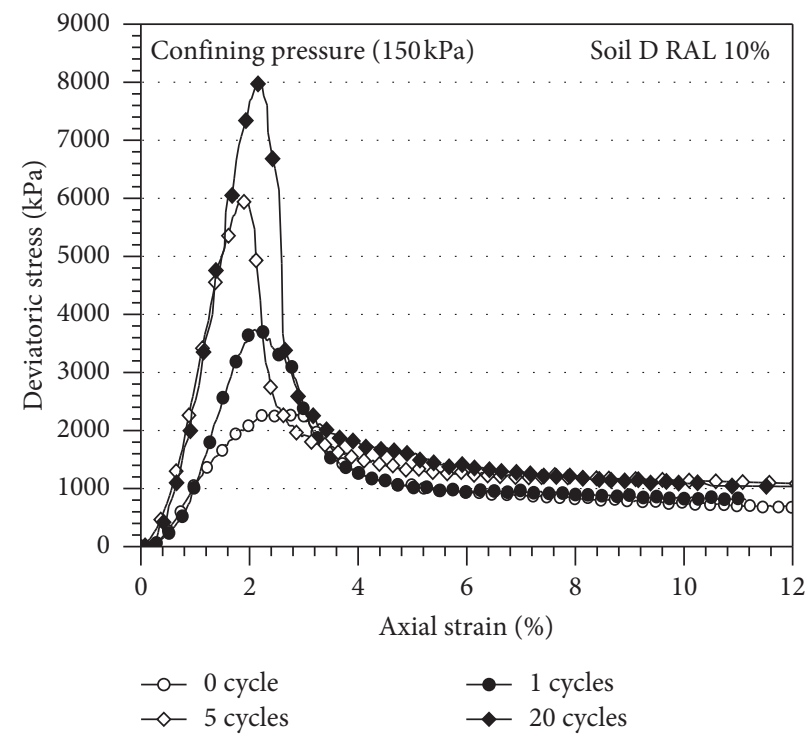

(l)

FIGURE 3: Stress-strain curves of the untreated and lime-stabilized specimens. 
behavior of the untreated specimens mainly performed as strain-softening (Figures 3(a)-3(c)). However, after the peak, the reduction in the stress with further strain increase was not obvious. Meanwhile, the W-D cycle further weakened this strain-softening behavior. With the confining presses of 100 and $150 \mathrm{kPa}$, the stress-strain behavior of the untreated specimens changed to strain-hardening after 5 and $20 \mathrm{~W}$-D cycles.

The lime-stabilized specimens all performed as strainsoftening (Figures 3(d)-3(1)), where the peak stress within these curves was obvious. After the peak, a significant stress reduction occurred as the strain increased further. When the strain reached $3-5 \%$, the stress maintained and did not change considerably with any strain increase. Then, a residual strength was reached. It is known that the size of particles and the strength of cementation are very important for the soil strength [24]. The addition of lime leads to a series of chemical replacement reactions in the soil. The products from these reactions bind the soil particles around them together and strengthen the soils significantly $[25,26]$. However, with the strain increase, the cementation provided by the cementation products breaks gradually. By comparing Figures 3(a)-3(c) and 3(d)-3(l), it can be seen that the residual strengths of the untreated and lime-stabilized specimens were very close. Thus, the stress reductions of the lime-stabilized specimens after the peak were significant. After the W-D cycles, the strain-softening behavior of the lime-stabilized specimens strengthened further. Compared with the untreated specimens, the failure strain of the limestabilized specimens decreased significantly.

\subsection{Effect of W-D Cycles on the Shear Strength and Strength} Parameters of Red Bed Soil. Variations in the shear strength of the untreated and lime-stabilized specimens with the $\mathrm{W}-\mathrm{D}$ cycles are shown in Figure 4. It is evident that the $\mathrm{W}$-D cycles had different effects on the shear strength of the untreated and the lime-stabilized specimens. For untreated specimens (Figure 4(a)), the shear strength decreased almost linearly with an increase in the W-D cycles. Without experiencing W-D cycles, the shear strength of the specimens ranged from 811 to $948 \mathrm{kPa}$ under three confining pressures. After experiencing one W-D cycle, reductions in the shear strength all exceeded $20 \%$. After $20 \mathrm{~W}$-D cycles, the maximum reduction in the shear strength was as much as $60.5 \%$.

For the lime-stabilized specimens with 3\% RAL (Figure 4(b)), the shear strength increased significantly compared to that of the untreated specimens. Without experiencing the W-D cycles, the shear strength of these specimens ranged from 1385 to $1757 \mathrm{kPa}$ under three confining pressures, which was about two times that of the untreated specimens. Meanwhile, the shear strength increased with the W-D cycles and then decreased. After 5 $\mathrm{W}-\mathrm{D}$ cycles, increases in the shear strength were as much as 163.2-183.6\%. After $20 \mathrm{~W}-\mathrm{D}$ cycles, although lower than that of the specimens experiencing $5 \mathrm{~W}$-D cycles, the shear strengths were greater than those of the specimens that did not experience the $\mathrm{W}-\mathrm{D}$ cycles.
While for the lime-stabilized specimens with RALs of 5\% and $10 \%$ (Figures $4(\mathrm{c})$ and $4(\mathrm{~d})$ ), the shear strength increased further compared to that for the untreated soils. The greater the RAL was, the greater the increase in the shear strength was. For example, without experiencing W-D cycles, the lime-stabilized specimens with $10 \%$ RAL had their shear strength ranging from 1982 to $2342 \mathrm{kPa}$, which were 2.5 to 3 times that of the untreated specimens. Furthermore, with increasing the $\mathrm{W}-\mathrm{D}$ cycles, the shear strength increased significantly. After $20 \mathrm{~W}$-D cycles, the increase in the shear strength of the lime-stabilized specimens with $10 \%$ RAL was close to $200 \%$.

Variations in the shear strength parameters of the untreated and lime-stabilized specimens with the W-D cycles are shown in Figure 5. It can also be observed that the W-D cycles had different effects on the shear strength parameters of the untreated and lime-stabilized specimens. For the untreated specimens, with increase in the W-D cycles, both the cohesion and the internal friction angle decreased considerably. After $20 \mathrm{~W}$-D cycles, the maximum reductions in the cohesion and internal friction angle were $67.4 \%$ and $34.1 \%$, respectively.

While for the lime-stabilized specimens with all the three RALs, the cohesion first decreased and then increased with the increase of the W-D cycles. After $20 \mathrm{~W}$-D cycles, increase in the cohesion of the lime-stabilized specimens ranged from $103.6 \%$ to $167.8 \%$. On the other hand, the internal friction angle of the lime-stabilized specimens increased firstly and then decreased with the W-D cycles. With the RAL of $3 \%$, the internal friction angle of the lime-stabilized specimens after $20 \mathrm{~W}$-D cycles was smaller than that of the specimens without experiencing the W-D cycle. By contrast, when the RALs were $5 \%$ and $10 \%$, the internal friction angle of the lime-stabilized specimens after $20 \mathrm{~W}-\mathrm{D}$ cycles was still greater than that of the specimens without experiencing the W-D cycle.

\subsection{Effect of W-D Cycles on the Shear Modulus of Red Bed Soil.} The shear modulus is defined as the ratio of the deviatoric stress to the corresponding axial strain at an elastic deformation stage on the stress-strain curve. Based on the definition, the shear moduli of the untreated and lime-stabilized specimens are calculated and shown in Figure 6. To save space, only the results with the confining pressure of $100 \mathrm{kPa}$ were presented. For the untreated specimens, the shear moduli decreased almost linearly with increase in the W-D cycles. After $20 \mathrm{~W}$-D cycles, the maximum reduction was as much as $66.5 \%$. Compared with that of the untreated specimens, the shear moduli of the lime-stabilized specimens increased considerably. Meanwhile, the greater the RAL was, the greater the increase in the shear modulus was.

Without experiencing the W-D cycles, the shear modulus of the lime-stabilized specimen with RAL of $3 \%$ was 65.3 Mpa. With increase in the W-D cycles, the shear modulus first increased and then decreased. After 5 W-D cycles, the increase in the shear modulus was $232.3 \%$. Moreover, after $20 \mathrm{~W}$-D cycles, the shear modulus was still greater than those specimens without experiencing the W-D 


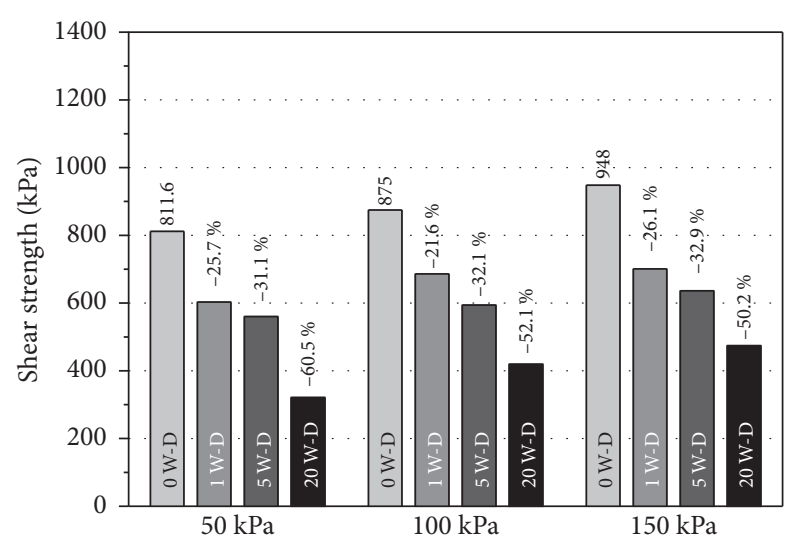

(a)

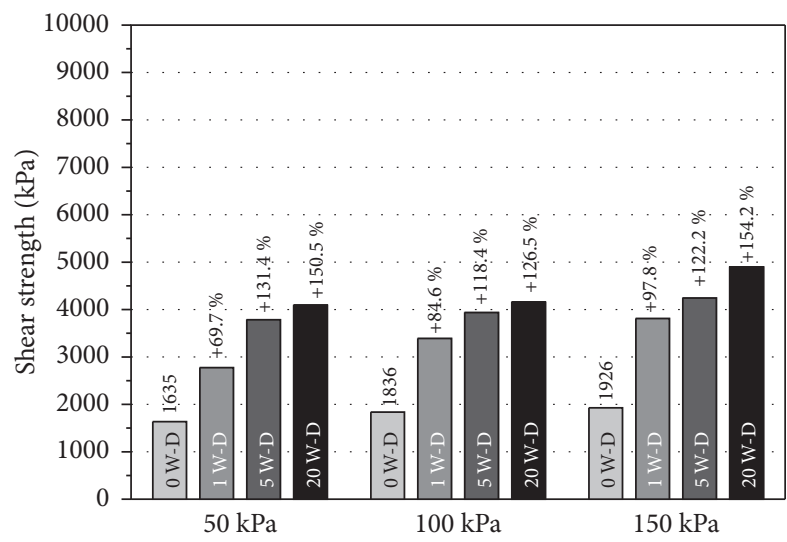

(c)

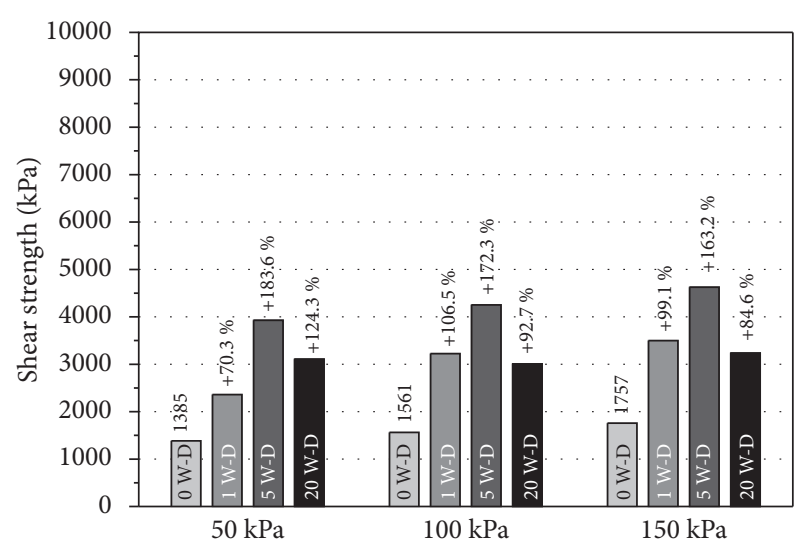

(b)

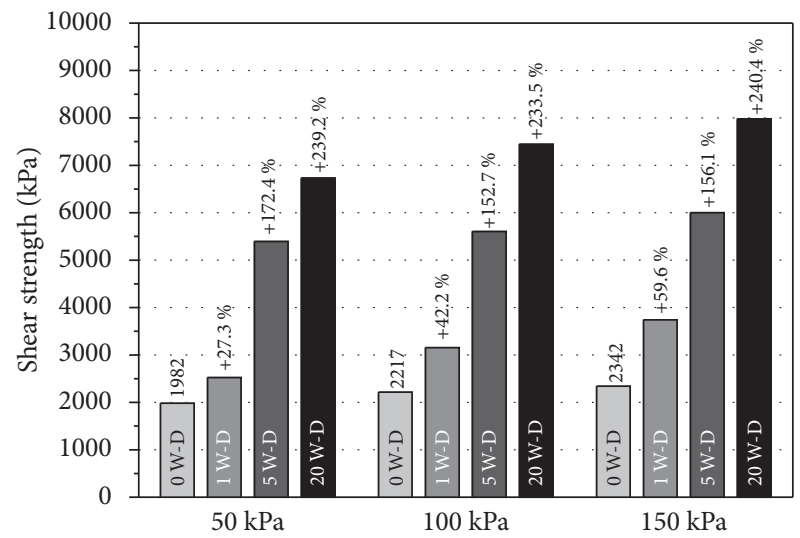

(d)

FIGURE 4: Variations in the shear strength of the untreated and lime-stabilized specimens with the W-D cycles: (a) RAL 0\%; (b) RAL 3\%; (c) RAL 5\%; (d) RAL10\%.

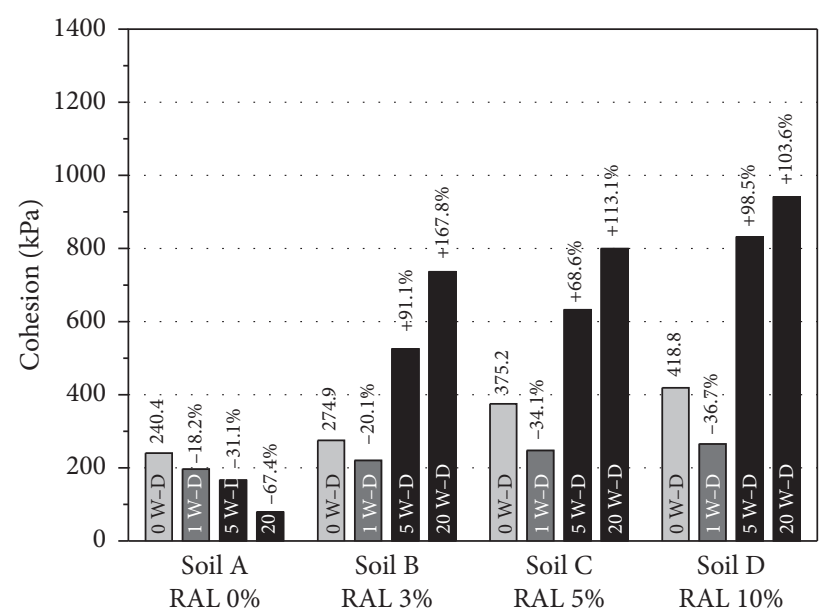

(a)

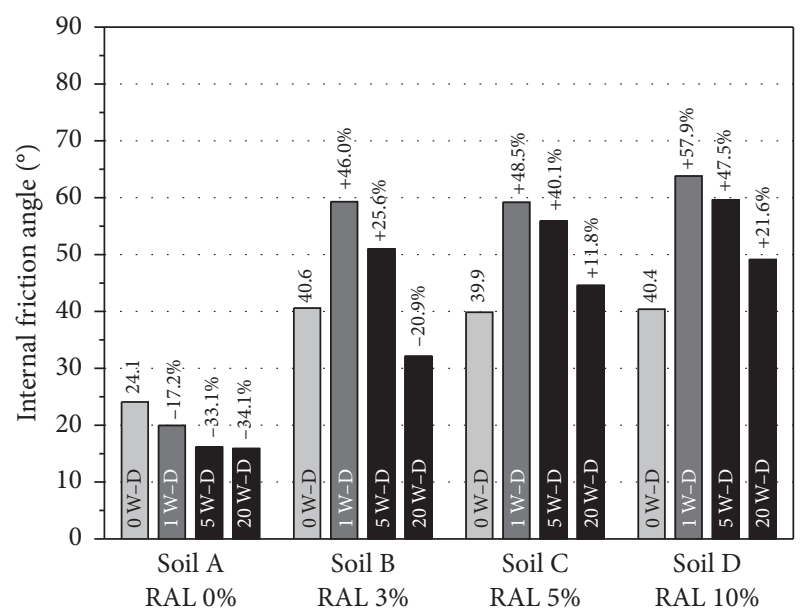

(b)

FIGURE 5: Variations in the shear strength parameters of the untreated and lime-stabilized specimens with the W-D cycles: (a) cohesion; (b) internal friction angle. 


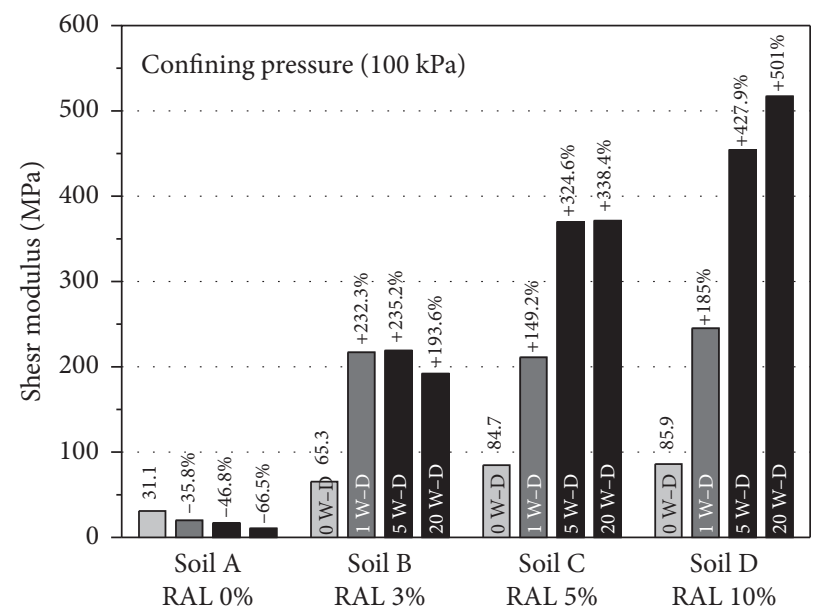

Figure 6: Shear moduli of the untreated and lime-stabilized specimens.

cycles. For lime-stabilized specimens with the RALs of 5\% and $10 \%$, the shear moduli increased continuously with increase in the W-D cycles. Without experiencing the W-D cycles, the lime-stabilized specimen with RAL of $10 \%$ had its shear modulus being about $85.9 \mathrm{MPa}$. After $20 \mathrm{~W}$-D cycles, the increase in the shear modulus was close to $500 \%$.

4.4. Effect of W-D Cycles on Permeability of Red Bed Soil. Variations in the permeability coefficients of the untreated and the lime-stabilized specimens (10\% RAL) with the W-D cycles are shown in Figure 7. For untreated specimens, the permeability coefficient increased significantly with an increase in the W-D cycles, which was $1.9 \times 10^{-8} \mathrm{~cm} / \mathrm{s}$ when there were no W-D cycles. After $5 \mathrm{~W}$-D cycles, it increased by more than one order and reached up to $1.2 \times 10^{-7} \mathrm{~cm} / \mathrm{s}$. This is because, with an increase in the W-D cycles, the quantity of free silt and clay particles progressively reduces as coarser particles are formed [27, 28], leading to larger void formations and an increase in permeability. By contrast, for lime-stabilized specimens with the 10\% RAL, the W-D cycles had a different effect on the permeability coefficient. With an increase in the W-D cycles, the permeability coefficient of the lime-stabilized specimens decreased exponentially. After $5 \mathrm{~W}$-D cycles, the permeability coefficient was only about $6.6 \times 10^{-9} \mathrm{~cm} / \mathrm{s}$. The decrease in the permeability coefficient was related to the void filling by the production from the lime hydrate reaction with the silica or alumina.

\subsection{Effect of W-D Cycles on Microstructure of Red Bed Soil.} The SEM analysis is conducted on the untreated and limestabilized triaxial specimens after different W-D cycles to observe the effect of lime treatment and W-D cycles on morphological structure.

The SEM images of untreated specimens under different W-D cycles are shown in Figure 8. Without experiencing the $\mathrm{W}-\mathrm{D}$ cycles, the structure of the soil particles was layered and lamellar with fewer voids. The specimens were relative dense. After the W-D cycles, the amount and size of the void increased gradually and the amount and size of large soil

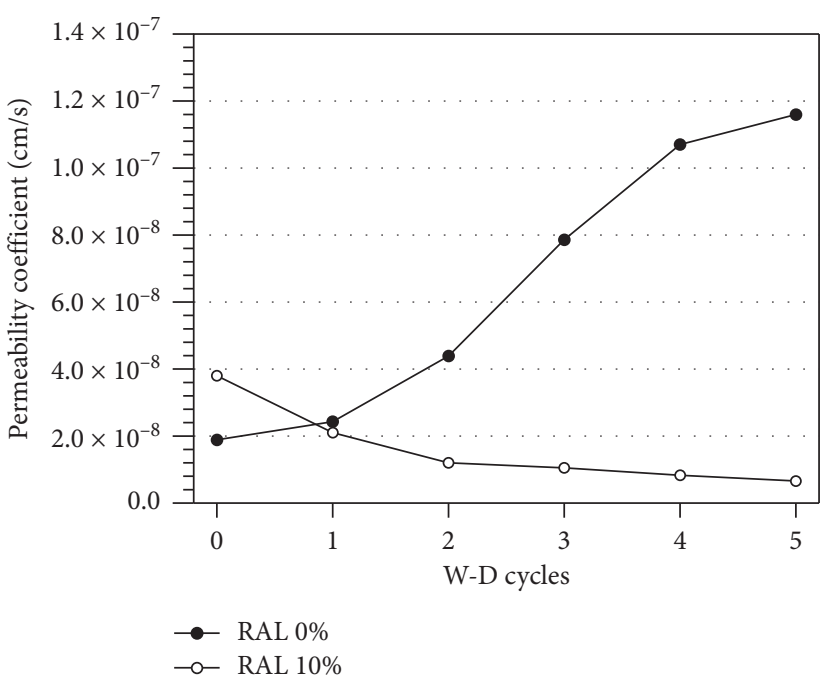

Figure 7: Variations in the permeability coefficients of the untreated and lime-stabilized specimens (10\% RAL) with the W-D cycles.

particles decreased. Then, the degree of aggregation of soil particles decreased considerably. The original layered and lamellar structures of the soil particle were broken, and the specimens became loose. These variations corroborate the decrease in the strength and the increase in the permeability of the specimens. The effects of W-D cycles on morphological structure above were also well confirmed by the mercury intrusion porosimetry test by Zeng et al. [29] and synchrotron-based X-ray microcomputed tomography tests and digital image analysis by $\mathrm{Ma}$ et al. [30].

The SEM images of lime-stabilized specimens with RALs of $3 \%$ and $10 \%$ under different W-D cycles are shown in Figures 9 and 10. Without experiencing the W-D cycles, some honeycomb network structures among soil particles developed after the addition of lime and are clearly visible in Figures 9(a) and 10(a). The greater the RAL was, the more the honeycomb network structures developed were. Previous X-ray diffraction analysis indicated that cementitious 


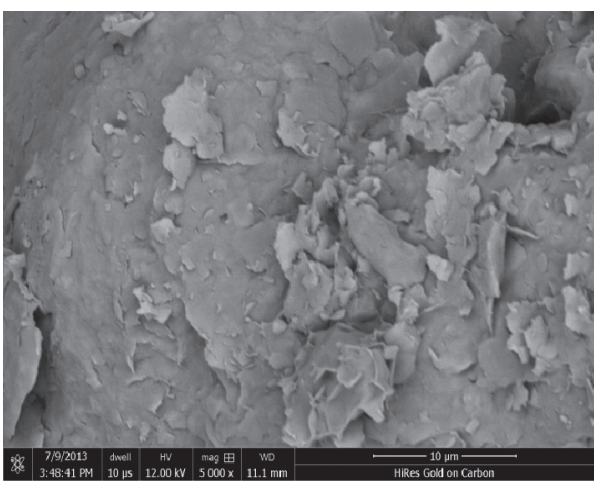

(a)

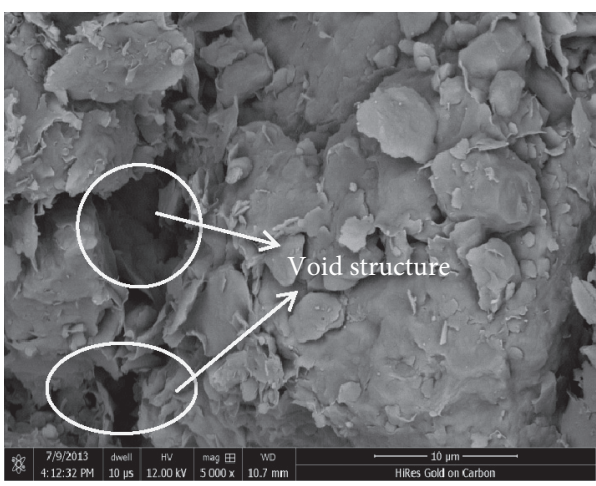

(c)

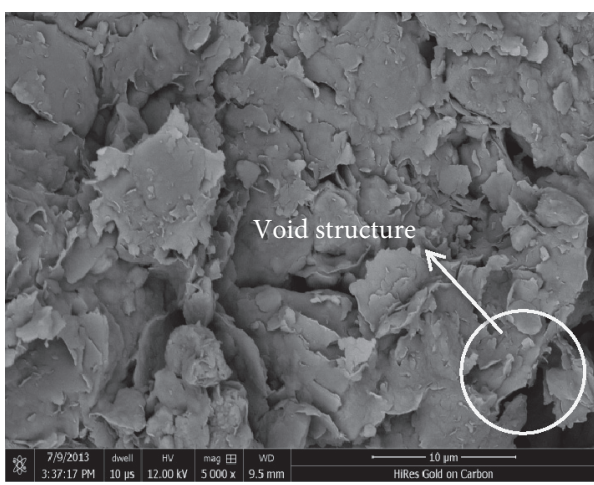

(b)

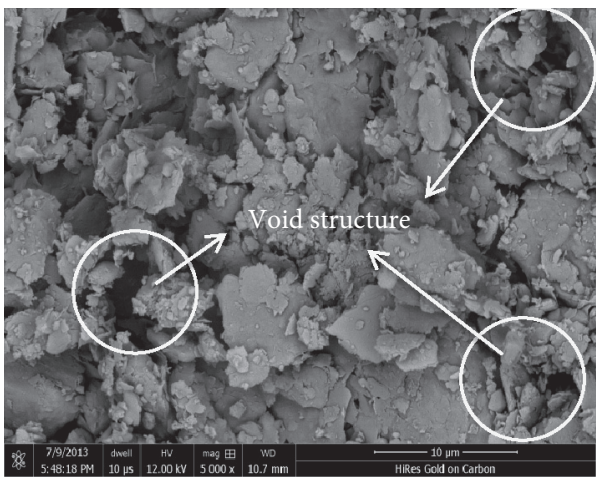

(d)

FIGURE 8: SEM images of untreated specimens under different W-D cycles: (a) 0 W-D cycle; (b) 1 W-D cycle; (c) 5 W-D cycles; (d) 20 W-D cycles.

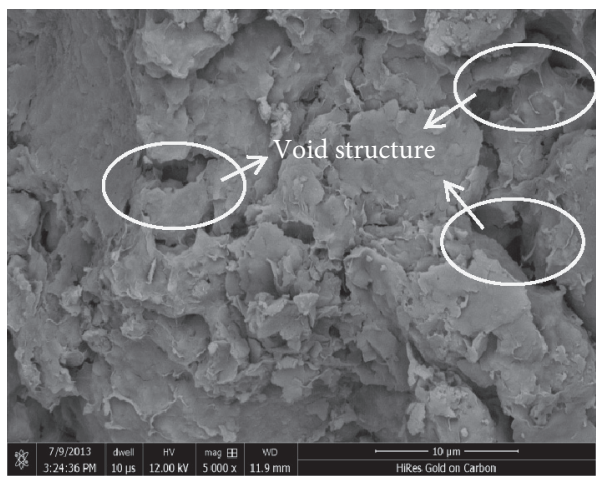

(a)

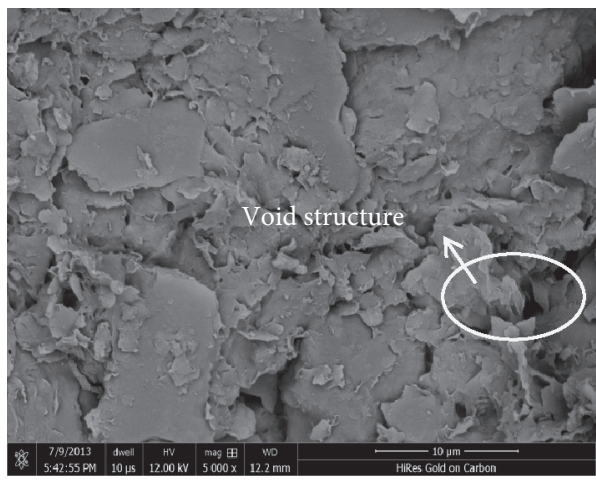

(c)

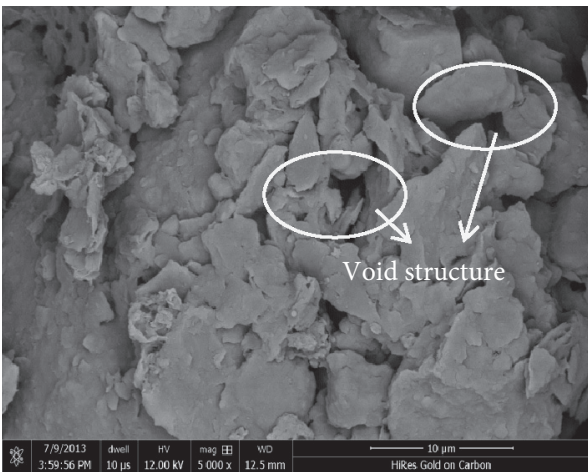

(b)

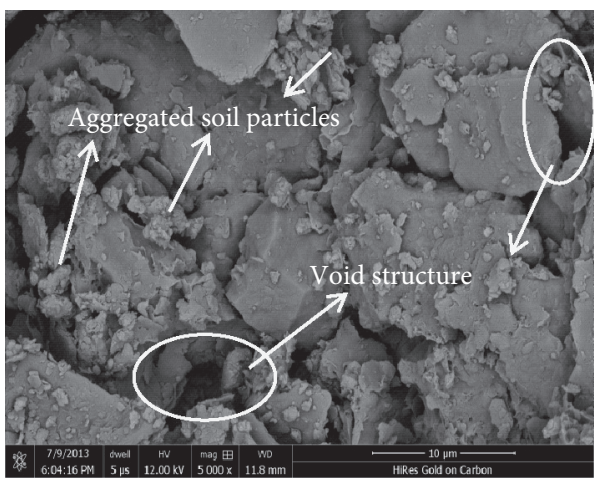

(d)

Figure 9: SEM images of lime-stabilized specimens with RAL of 3\% under different W-D cycles: (a) 0 W-D cycle; (b) 1 W-D cycle; (c) 5 W-D cycles; (d) $20 \mathrm{~W}-\mathrm{D}$ cycles. 


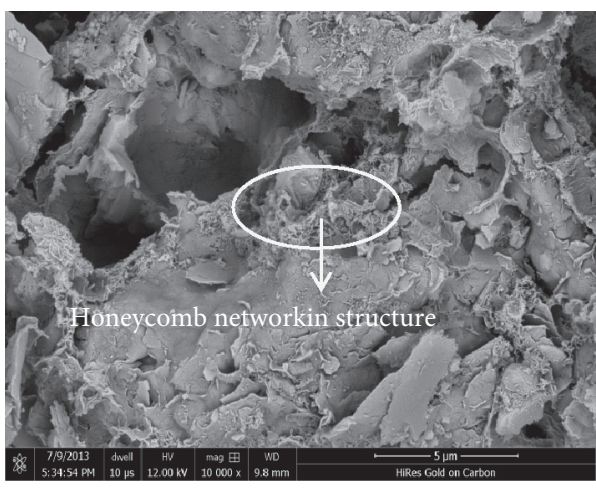

(a)

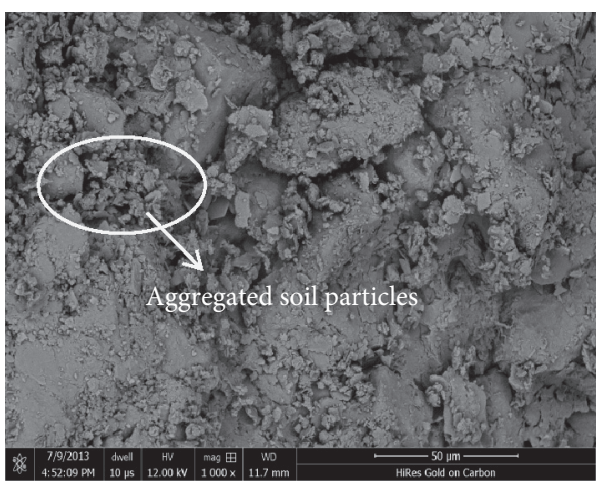

(c)

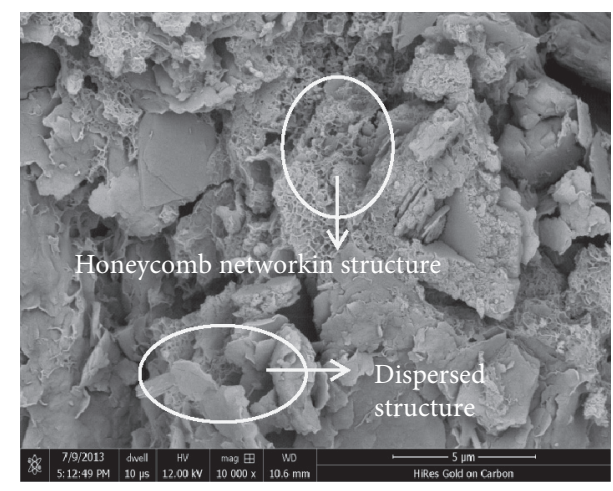

(b)

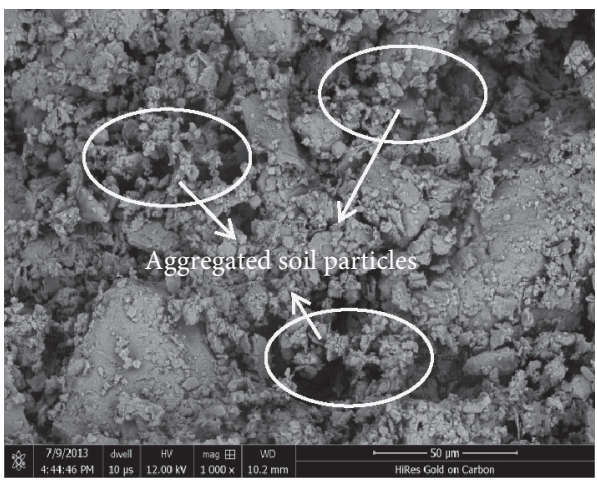

(d)

Figure 10: SEM images of lime-stabilized specimens with RAL of $10 \%$ under different W-D cycles: (a) 0 W-D cycle; (b) 1 W-D cycle; (c) $5 \mathrm{~W}$-D cycles; (d) $20 \mathrm{~W}$-D cycles.

compounds (e.g., CAH and $\mathrm{CSH}$ ) formed from a serious of reactions between lime and soil [31-33]. Meanwhile, more voids were formed in soils as the soil particles were aggregated together. This agrees with the strength improvement of and the increase of the permeability of the specimens with addition of lime. When the RAL was $3 \%$, the reactions went on with the increase in $\mathrm{W}$-D cycles but almost finished after $5 \mathrm{~W}$-D cycles. With further increase in the W-D cycles, the stability of the cementation among soil particles decreased, leading to a decrease in the strength of the specimens. While for the RAL of $10 \%$, the reactions between lime and soil went on with the increase in W-D cycles. A great amount of aggregated soil particles formed from the honeycomb network structures and blocked the voids gradually. Thus, the permeability coefficient decreased with the increase in W-D cycles.

\section{Conclusions}

The objective of this study was to investigate effects of the W-D cycles on the mechanical properties and microstructure of untreated and lime-stabilized red bed soils. Based on laboratory test results, the conclusions can be drawn as follows:

(1) The untreated specimens mainly performed as weak strain-softening. After experiencing the W-D cycles, the strain-softening behavior of the untreated specimens was further weakened and even changed to strainhardening under larger confining pressures. The lime- stabilized specimens all performed as strain-softening, and the stress reduction after the peak increased considerably after experiencing the W-D cycles.

(2) Both the strength and permeability properties of the lime-stabilized specimens improved considerably. After experiencing the cyclic W-D, the shear strength, strength parameters, and the shear moduli of the untreated and lime-stabilized specimens decreased considerably and increased gradually, respectively. The permeability coefficient of the untreated and lime-stabilized specimens continuously increased and significantly decreased, respectively, with an increase in the W-D cycles.

(3) SEM analysis demonstrated that the interior of the specimens changed from layered and lamellar structure to continuous honeycomb networking structure after lime stabilization. With an increase in the W-D cycles, the layered and lamellar broke step by step, and many dispersed structures formed. The honeycomb networking structure also gradually flocculated and aggregated into granular solids with the W-D cycles.

\section{Data Availability}

The data used to support the findings of this study are available from the corresponding author upon request. 


\section{Conflicts of Interest}

The authors declare no conflicts of interest.

\section{Authors' Contributions}

Yuncheng Mao and Yanhu Mu conceived and designed the experiments. Zhengmin Song, Dewen Zhang, Kun Zhang, and Qinglong Zhang performed the experiments. Zhengmin Song analyzed the data and wrote the paper.

\section{Acknowledgments}

This work was supported by the Science and Technology Project of Gansu Provincial Transportation Department (no. 201600009), the Instrument Development Project of Chinese Academy of Sciences (no. 28Y928581), the Fund of the State Key Laboratory of Frozen Soil Engineering (no. SKLFSE201603), and the Science and Technology Project of Yalong River Hydropower Development Company (no. LHKA-G201701).

\section{References}

[1] Z. X. Pan and H. Peng, "Comparative study on the global distribution and geomorphic development of red beds," Scientia Geographica Sinica, vol. 35, pp. 1575-1584, 2015.

[2] Q. Cheng, X. B. Kou, S. B. Huang, and Y. J. Zhou, "The distributes and geologic environment characteristics of red beds in China," Journal of Engineering Geology, vol. 12, pp. 34-40, 2004.

[3] C. Y. Zhou, X. Yang, Y. H. Liang et al., "Classification of redbed rock mass structures and slope failure modes in South China," Geosciences, vol. 9, no. 6, p. 273, 2019.

[4] T. M. Petry and D. N. Little, "Review of stabilization of clays and expansive soils in pavements and lightly loaded structures-history, practice, and future," Journal of Materials in Civil Engineering, vol. 14, no. 6, pp. 447-460, 2002.

[5] Z. Zhang, Q. Jiang, C. Zhou, and X. Liu, "Strength and failure characteristics of jurassic red-bed sandstone under cyclic wetting-drying conditions," Geophysical Journal International, vol. 198, no. 2, pp. 1034-1044, 2014.

[6] A. L. Mukhtar, L. Abdelmadjid, and J. F. Alcover, "Behaviour and mineralogy changes in lime-treated expansive soil at 20 C," Applied Clay Science, vol. 50, no. 50, pp. 191-198, 2010.

[7] J. Zhang, G. Niu, X. Li, and D. a. Sun, "Hydro-mechanical behavior of expansive soils with different dry densities over a wide suction range," Acta Geotechnica, vol. 15, no. 1, pp. 265-278, 2019.

[8] J. James and P. K. Pandian, "Plasticity, swell-shrink, and microstructure of phosphogypsum admixed lime stabilized expansive soil," Advances in Civil Engineering, vol. 2016, pp. 1-10, 2016.

[9] J. R. Zhang, T. Jiang, X. C. Wang, C. Liu, and Z. Q. Huang, "Influences of drying and wetting cycle and compaction degree on strength of Yudong silt for subgrade and its prediction," Advances in Civil Engineering, vol. 2018, Article ID 1364186, 10 pages, 2018.

[10] A. A. Al-Rawas, A. W. Hago, and H. Al-Sarmi, "Effect of lime, cement and sarooj (artificial pozzolan) on the swelling potential of an expansive soil from Oman," Building and Environment, Building and Environment, vol. 40, no. 5, pp. 681-687, 2005.
[11] J. Zhang, D. a. Sun, H. Yu, J. Jiang, and Y. Xu, "Swelling of unsaturated GMZ07 bentonite at different temperatures," Bulletin of Engineering Geology and the Environment, vol. 79, no. 2, pp. 959-969, 2019.

[12] J. P. Sahoo and P. K. Pradhan, "Effect of lime stabilized soil cushion on strength behaviour of expansive soil," Geotechnical and Geological Engineering, vol. 28, no. 6, pp. 889-897, 2010.

[13] M. Khemissa and A. Mahamedi, "Cement and lime mixture stabilization of an expansive overconsolidated clay," Applied Clay Science, vol. 95, pp. 104-110, 2014.

[14] S. M. Rao, B. V. V. Reddy, and M. Muttharam, "The impact of cyclic wetting and drying on the swelling behaviour of stabilized expansive soils," Engineering Geology, vol. 60, no. 1-4, pp. 223-233, 2001.

[15] H. Ye, C. Chu, L. Xu, K. Guo, and D. Li, "Experimental studies on drying-wetting cycle characteristics of expansive soils improved by industrial wastes," Advances in Civil Engineering, vol. 2018, pp. 1-9, 2018.

[16] B. Wang, C. Zhang, X. Qiu, E. Ji, and W. Zhang, "Research on wetting-drying cycles effect on the physical and mechanical properties of expansive soil improved by OTAC-KCl," Advances in Materials Science and Engineering, vol. 2015, Article ID 304276, 7 pages, 2015.

[17] Y. Guney, D. Sari, M. Cetin, and M. Tuncan, "Impact of cyclic wetting-drying on swelling behavior of lime-stabilized soil," Building and Environment, vol. 42, no. 2, pp. 681-688, 2007.

[18] F. Akcanca and M. Aytekin, "Effect of wetting-drying cycles on swelling behavior of lime stabilized sand-bentonite mixtures," Environmental Earth Sciences, vol. 66, no. 1, pp. 67-74, 2012.

[19] F. Yazdandoust and S. S. Yasrobi, "Effect of cyclic wetting and drying on swelling behavior of polymer-stabilized expansive clays," Applied Clay Science, vol. 50, no. 4, pp. 461-468, 2010.

[20] GB/T JTJ013-95, Highway Soil Test Procedures, Ministry of Construction, China, 1995.

[21] GB/T 50123-2019, Standard for Geotechnical Testing Method, Ministry of Construction, China, 2019.

[22] F. G. Bell, "Lime stabilization of clay minerals and soils," Engineering Geology, vol. 42, no. 4, pp. 223-237, 1996.

[23] ASTM D2850-15, Standard Specification for UnconsolidatedUndrained Triaxial Compression Test on Cohesive Soils, ASTM International, West Conshohocken, PA, USA, 2015.

[24] E. Garzon, M. Cano, B. C. O. Kelly, and P. J. Sánchez-Soto, "Effect of lime on stabilization of phyllite clays," Applied Clay Science, vol. 123, pp. 329-334, 2016.

[25] P. K. Mathew and S. N. Rao, "Effect of lime on cation exchange capacity of marine clay," Journal of Geotechnical and Geoenvironmental Engineering, vol. 123, no. 2, pp. 183-185, 1997.

[26] K. D. Sujit and H. Monowar, "Lime stabilization of soils: reappraisal," Journal of Materials in Civil Engineering, vol. 24, pp. 707-714, 2012.

[27] T. C. B. Galvao, A. Elasharief, and G. F. Simo, "Effects of lime on permeability and compressibility of two tropical residual soils," Journal of Environmental Engineering, vol. 130, pp. 881-885, 2004.

[28] G. Rajasekaran and S. Narasimha Rao, "Permeability characteristics of lime treated marine clay," Ocean Engineering, vol. 29, no. 2, pp. 113-127, 2002.

[29] Z. T. Zeng, H. B. Lu, Y. L. Zhao, and Z. B. Wang, "Study of pore size distribution of expansive soil during wetting-drying cycle and its application," Rock and Soil Mechanics, vol. 34, pp. 322-328, 2013. 
[30] R. Ma, C. Cai, Z. Li et al., "Evaluation of soil aggregate microstructure and stability under wetting and drying cycles in two Ultisols using synchrotron-based X-ray micro-computed tomography," Soil and Tillage Research, vol. 149, pp. 1-11, 2015.

[31] P. V. Sivapullaiah and A. K. Jha, "Gypsum induced strength behaviour of fly Ash-Lime stabilized expansive soil," Geotechnical and Geological Engineering, vol. 32, no. 5, pp. 1261-1273, 2014.

[32] M. Al-Mukhtar, S. Khattab, and J.-F. Alcover, "Microstructure and geotechnical properties of lime-treated expansive clayey soil," Engineering Geology, vol. 139-140, pp. 17-27, 2012.

[33] L. F. Pires, A. C. Auler, W. L. Roque, and S. J. Mooney, "X-ray microtomography analysis of soil pore structure dynamics under wetting and drying cycles," Geoderma, vol. 362, pp. 1-10, 2020. 